\title{
Desafios e oportunidades na saúde digital
}

\author{
Challenges and opportunities in digital health
}

Desafíos y oportunidades en salud digital

\author{
Ana O. Franco 1 \\ M. Gabriela M. Gomes 2
}

doi: 10.1590/0102-311X00090417

$\mathrm{O}$ artigo de Leal Neto et al. tem como foco o crescimento tecnológico exponencial e as consequentes alterações nos atuais paradigmas das ciências da saúde. O texto cita vários casos em concreto, na perspectiva das "inovações disruptivas" e o seu impacto na saúde pública.

Neste comentário iremos debruçar-nos sobre alguns dos casos citados por Leal Neto et al., complementando a sua exposição com exemplos adicionais, refletindo sobre alguns desafios e oportunidades inerentes à saúde digital.

Parece-nos importante começar por clarificar o conceito de "inovações disruptivas”, para quem seja menos familiarizado com o termo. Não se trata apenas de algo simplesmente inovador, mas sim do processo por meio do qual um produto ou serviço introduzido como aparentemente simples, e pouco apelativo comparativamente com os líderes de mercado, consegue, devido ao seu menor custo e maior conveniência e facilidade de utilização, vir a causar uma reviravolta no mercado, gerando uma nova rede de valor com uma nova população de consumidores, e escalando eventualmente até ao topo do mercado. Para conseguir alcançar essa escala e sustentabilidade, é vital que a inovação tecnológica seja acoplada a um modelo de negócio inovador, à semelhança do que acontece no mundo empresarial 1.

Uma das inovações metodológicas citadas é o crowdsourcing, em que a população contribui com informação para a resolução de um problema, e há depois um retorno à população do conhecimento coletivo que foi gerado com o contributo de todos.

Salientamos um dos casos de estudo baseado nessa metodologia: a detecção digital de doenças utilizando a vigilância participativa, em que o cidadão é convidado a reportar voluntariamente informação sobre o seu estado de saúde, por meio do preenchimento de um questionário de sintomas via Internet, permitindo complementar a informação recolhida tradicionalmente pelas unidades de saúde. Esse sistema começou a ser utilizado para monitorizar a gripe na Holanda em 2003, expandindo-se rapidamente pela Europa (dez países europeus integram atualmente o consórcio Influenzanet) e outros continentes 2 .

Em Portugal e na Inglaterra esse sistema foi desenvolvido por pesquisadores de institutos de investigação científica, tendo sido recentemente adotado pelos respectivos Institutos Nacionais de Saúde (que são as entidades responsáveis pela vigilância da gripe). É um exemplo de como uma inovação tecnológica que começou como um projeto de ciência cidadã foi adotada pelo sistema nacional de saúde, e que os resultados poderão vir a ser usados nas tomadas de decisão e políticas de saúde.
1 London School of Hygiene and Tropical Medicine, London, U.K.

2 Liverpool School of Tropical Medicine, Liverpool, U.K.

Correspondência M. G. M. Gomes Liverpool School of Tropical Medicine.

Pembroke Place, Liverpool England, L3 5QA, U.K. gabriela.gomes@lstmed.ac.uk 
Uma outra forma de crowdsourcing é a utilização de informação providenciada indiretamente pela população por meio de fontes variadas, como mensagens nas redes sociais (e.g. Facebook, Twitter, Instagram) e/ou termos de pesquisas realizadas na Internet, analisados por métodos de Inteligência Artificial e Aprendizado de Máquina. É importante referir que, se por um lado esses meios oferecem um enorme manancial de dados, obtidos com facilidade (big data), por outro desafiam as metodologias de análise para certificar que os dados refletem de fato a ocorrência da doença em questão, e que não são apenas reflexo de outras circunstâncias. Um exemplo desse caso ocorreu com o Google Flu Trends, que em vários anos conseguiu estimar razoavelmente bem a intensidade da epidemia de gripe, mas noutras épocas fez sobrestimações por utilizar os mesmos algoritmos de anos anteriores, sem ter em conta outros fatores como o aumento de pesquisas relacionadas com a gripe devido à maior ênfase nas notícias sobre a doença 3 .

O sistema de vigilância participativa Influenzanet foi também adaptado para monitorizar outras doenças infecciosas, nomeadamente dengue (www.denguenaweb.org) na cidade de Salvador, Bahia, Brasil, e sistemas semelhantes sob a forma de aplicativos para celular foram desenvolvidos para o Mundial de Futebol de 2014 "Saúde na Copa” e os Jogos Olímpicos de 2016 no Brasil "Guardiões da Saúde" 4. Essas ferramentas têm o potencial de ser utilizadas por todo o Brasil, e de ser customizadas para permitir também a monitorização de casos suspeitos de Zika e Chikungunya (que têm sintomatologia semelhante à do dengue e são transmitidos pelo mesmo vetor). Curiosamente, nem o vetor fica fora da cobertura das novas metodologias. "Radar Cidadão", disponível em todo o Brasil, é um aplicativo para celular que também tem uma página web (radarcidadao.com.br), para reportar potenciais locais de criação de mosquitos Aedes. O aplicativo permite também reportar outras ocorrências na área da saúde, educação, segurança, acessibilidade etc., para que as entidades responsáveis tomem conhecimento e otimizem a sua atuação.

Os aplicativos para celulares na área da saúde são outras inovações que têm aumentado exponencialmente, não só os destinados ao público em geral, mas também os especializados para os profissionais de saúde, como forma de melhor os capacitar e/ou de otimizar o fluxo de informação com as unidades centrais de saúde.

É de salientar um aplicativo para celular que foi recentemente desenvolvido pela Organização Mundial da Saúde (OMS) "WHO Zika App" (http://www.who.int/risk-communication/zikavirus/ app/en/), que inclui informação essencial sobre esta doença (e.g. prevenção, sintomas, complicações, diagnóstico, notícias), para melhor capacitar os profissionais de saúde e manter também a população mais informada, estando disponível em várias línguas além do Português.

A utilidade e relevância dessas ferramentas são de grande valor. No entanto, seria importante encontrar um modo para haver maior integração entre diferentes ferramentas. Por exemplo, em vez de ser necessário instalar individualmente diferentes aplicativos específicos, cada um para a sua doença, poderia ser mais eficiente se houvesse um aplicativo com uma plataforma em que fosse disponibilizada informação sobre várias doenças, como as consideradas mais problemáticas numa região, que pudesse ser facilmente atualizada com informação sobre possíveis novas doenças que viessem a ocorrer.

Apesar de os aplicativos anteriormente mencionados terem sido desenvolvidos por instituições de investigação científica e/ou de saúde pública, existe uma miríade de aplicativos em diversas áreas da saúde, produzidos por muitas outras entidades. Para além de ser necessário validar a qualidade dos dados providenciados pelo público, é importante assegurar também a regulamentação das inovações que vão surgindo, não só no nível da qualidade da informação que é oferecida aos seus usuários, mas também no nível da privacidade dos dados que são providenciados pelas pessoas, por vezes sem o seu próprio conhecimento. Este é um desafio, e uma área que necessita maior atenção face ao número exponencial de aplicativos para a saúde que tem sido produzido por entidades de credibilidade variada. Por exemplo, existem atualmente mais de 10 mil aplicativos relacionados com saúde mental disponíveis para instalação em celulares ou tabletes e, apesar de muitas destas ferramentas serem úteis e baseadas em evidência clínica, existem outras que disponibilizam informação que pode ser prejudicial à saúde 5 .

Concluímos fazendo menção a um exemplo mais ativo de crowdsourcing, que é o envolvimento das comunidades afetadas pelos problemas na criação de conteúdo educativo de promoção de comportamentos saudáveis (vídeos, imagens, slogans) e na sua disseminação ao público em geral, incluindo 
subgrupos minoritários e/ou marginalizados. É uma metodologia que começou recentemente a ser utilizada, sendo recomendada pela OMS (por exemplo, para promover a testagem de hepatite e HIV/ AIDS) por ter sido provado que os materiais produzidos deste modo inovador conseguem ser tão ou mais eficazes, e muito mais econômicos, do que os recursos elaborados por peritos externos contratados para executá-los 6 .

\section{Colaboradores}

A. O. Franco e M. G. M. Gomes foram responsáveis pela redação do artigo.
1. Hwang J, Christensen CM. Disruptive innovation in health care delivery: a framework for business-model. Health Aff (Millwood) 2008; 27:1329-35.

2. van Noort SP, Codeço CT, Koppeschaar CE, van Ranst M, Paolotti D, Gomes MG. Ten-year performance of Influenzanet: ILI time series, risks, vaccine effects, and care-seeking behaviour. Epidemics 2015;13:28-36.

3. Butler D. When Google got flu wrong. Nature 2013 494:155-6.

4. Leal Neto O, Dimech GS, Libel M, de Souza WV, Cesse E, Smolinski M, et al. Saúde na Copa: the world's first application of participatory surveillance for a mass gathering at FIFA World Cup 2014, Brazil. JMIR Public Health Surveill 2017; 3:e26.

5. Torous J, Roberts LW. Needed innovation in digital health and smartphone applications for mental health transparency and trust. JAMA Psychiatry 2017; 74:437-8.

6. Social Entrepreneurship for Sexual Health. What we do. http://www.seshglobal.org/whatwe-do (acessado em 25/Mai/2017). 